\title{
SPINAL CORD INJURIES AS A RESULT OF MOTORCYCLE ACCIDENTS
}

\author{
By R. D. Shrosbree, M.B., Ch.B. \\ Senior Medical Officer, Spinal Cord Injury Centre, Conradie Hospital, \\ Pinelands, Cape, Republic of South Africa
}

Abstract. The orthopaedic and neurological lesions of $2 \mathrm{I}$ cases of spinal cord injuries as a result of motorcycle accidents are reviewed. The thoracic spine and spinal cord were the site of injury in 76 per cent of cases. Eighty-one per cent of the thoracic injuries showed complete neurological lesions. A mechanism of injury is postulated.

Key words: Spinal injuries; Spinal cord injuries; Motorcycle accidents; Paraplegia.

\section{Introduction}

SPINAL cord injuries as a result of motorcycle accidents form a small, but increasing proportion of the cases admitted to the Spinal Cord Injuries Centre at the Conradie Hospital. Between I963 and I977, 21 cases have been admitted. These form approximately 3 per cent of the total number of spinal cord injuries admitted as a result of motor vehicle accidents of all types during the same period. The motorcycle is becoming an increasingly popular means of transport and since the spinal injuries due to motorcycle accidents appear to maximally involve a particular region of the vertebral column, a retrospective study of these cases was undertaken to confirm this impression and for further evaluation of this type of injury.

\section{Material}

During the period November I963 to March 1977, I870 new spinal cord lesions were admitted to the Spinal Unit (Table I). Of these 7 I 4 cases ( 38 per cent) were the result of motor vehicle accidents involving drivers, passengers, cyclists and pedestrians. Twenty-one ( 3 per cent of motor vehicle accidents) were due to motorcycle accidents. These included 17 riders and four pillion passengers. Two of the pillion passengers were females, the only females in the series.

Only three of the cases were injured while on duty.

TABLE I

\begin{tabular}{lrr}
\hline Total admissions, I963-77 & I870 & \\
Motor vehicle accidents & $7 \mathrm{I} 4$ & $38 \%$ \\
Motorcycle accidents & & I $\%$ \\
$\quad$ Riders & I7 & \\
Passengers (Male) & 2 & \\
$\quad$ (Female) & 2 & \\
Total & 2I & \\
\hline
\end{tabular}




\section{Age Incidence}

The age incidence was distributed as shown in Table II. The ages ranged from 17 to 55 years (average 27 years). There is a definite peak in the age group I 5 to 20 years, with a smaller peak in the age group 2 I to 25 years. A high incidence (66 per cent) was present in young people under the age of 25 years.

\section{Types of Accident}

In seven cases ( 33.3 per cent) another vehicle-an automobile-was involved (Table III). Two cases rode into the rear of a vehicle, three cases were struck by an automobile (all three were on duty at the time) and two cases struck an automobile which had turned in front of them.

Four cases (I9 per cent) hit fixed objects (trees, poles, pavement or drums) and a further four cases were involved in accidents as a result of skids or running off the road. These latter four cases admitted to speed as the primary cause of their accidents. Another three cases fell off their motorcycles-one had a 'blackout' and one was under the influence of alcohol.

No details were available on the remaining three cases.

TABLE II

Age incidence

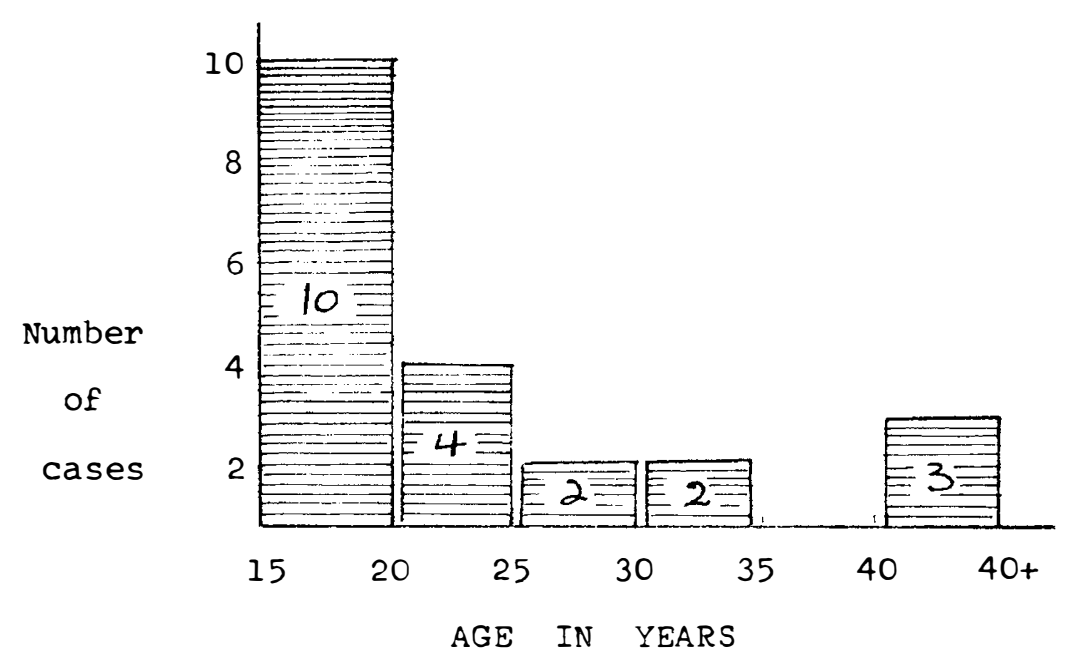

TABLE III

Type of accident

\begin{tabular}{lll}
\hline Hitting another vehicle & 7 & $33.3 \%$ \\
Hitting fixed object & 4 & $19 \%$ \\
Skids & 4 & $19 \%$ \\
Falls off motorcycle & 3 & $14.2 \%$ \\
No details & 3 & - \\
\hline
\end{tabular}


TABLE IV

Seasonal incidence

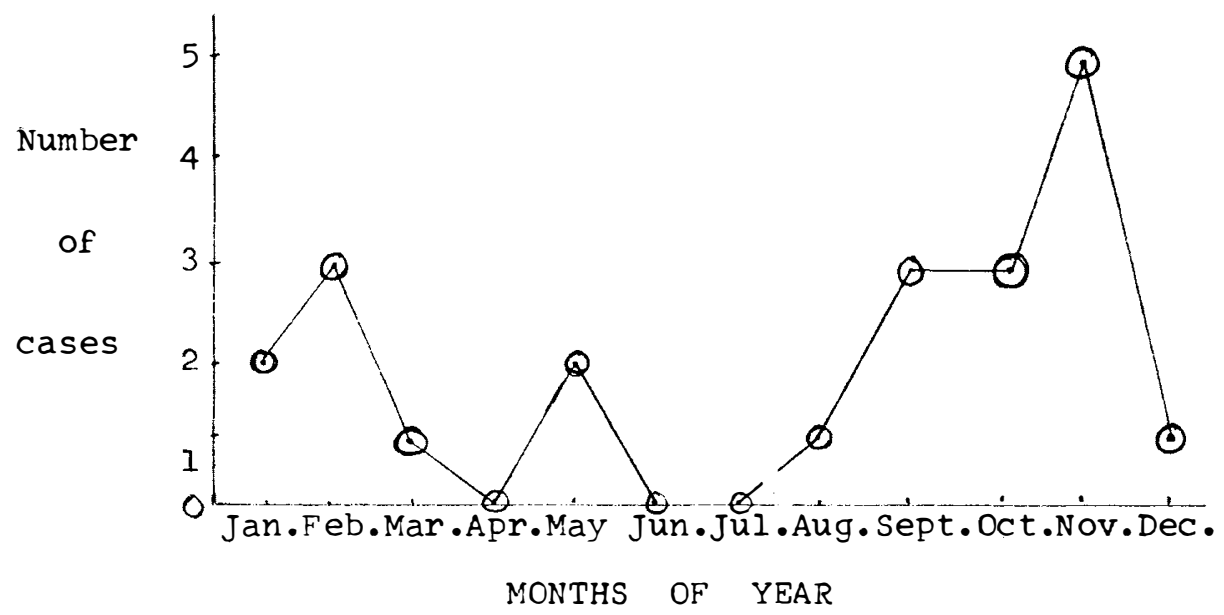

The machines varied in size from 50 to $750 \mathrm{cc}$ and included motor-scooters.

There was a definite seasonal incidence; most accidents occurred during the summer months, particularly November (Table IV).

\section{Orthopaedic Injuries}

All orthopaedic vertebral lesions involved the cervical and/or dorsal spine only (Table V).

Five cases (23.8 per cent) had cervical fractures or fracture-dislocations with corresponding neurological lesions. One had bilateral facet-interlocking, two had unilateral facet-interlocking and two had compression fractures (Fig. I).

The 16 other cases ( 77 per cent) involved the dorsal spine with corresponding neurological levels. In two of these cases both the dorsal and cervical spines were involved (Table VI), but the neurological lesion was thoracic (Figs. I and 2). These have been termed 'double lesions'. Twelve cases had more than one thoracic vertebra involved.

Eight cases had single or multiple compression fractures with no dislocation and no apparent disruption of the posterior ligament complex (Figs. 3 and 4). (Both double lesions had compression fractures at both levels.) The remaining eight cases had varying degrees of dislocation with complete disruption of a vertebra due to a possible shearing force (Fig. 5).

The thoracic vertebral lesions were all between the third ( $\left.\mathrm{T}_{3}\right)$ and the eighth (T8) thoracic vertebral with a single exception of one case with a fracture at the tenth thoracic vertebra. Compression fractures most frequently involved the sixth thoracic vertebra, followed by the fifth.

\section{Neurological Lesions}

The neurological levels more or less coincided with the vertebral injuries (Table VII). The discrepancy between the peak incidences on the graphs denoting 


\section{TABLE V}

Type of fracture

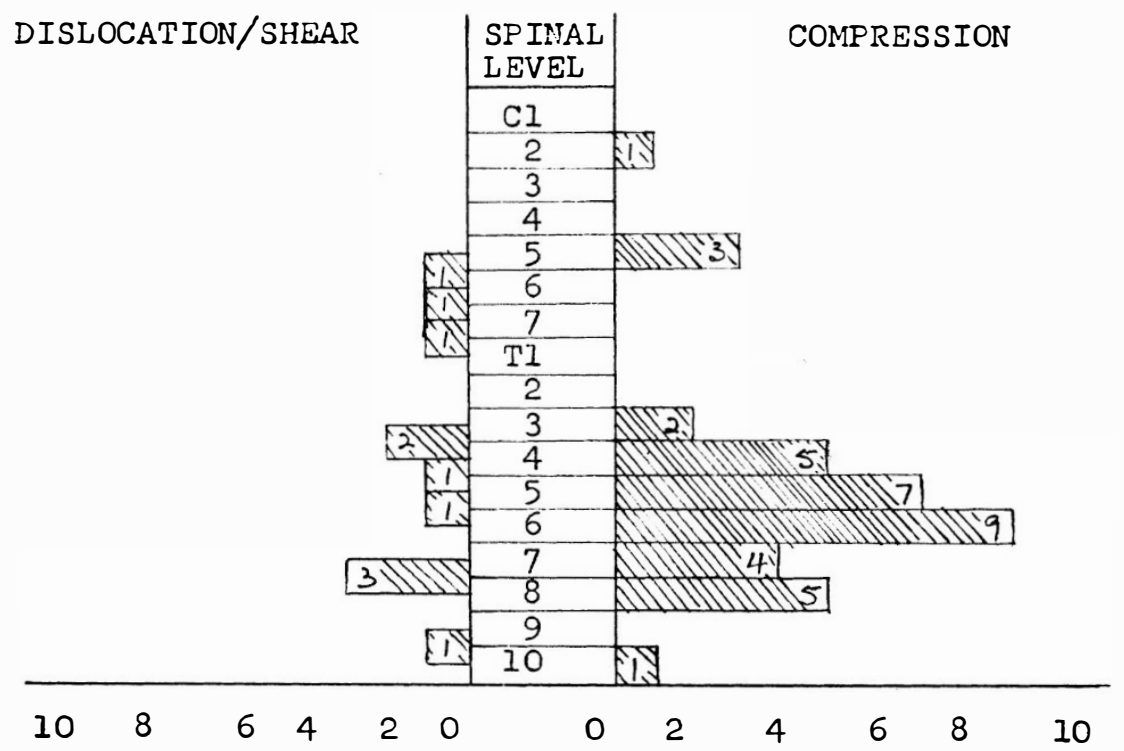

NUMBER OF CASES
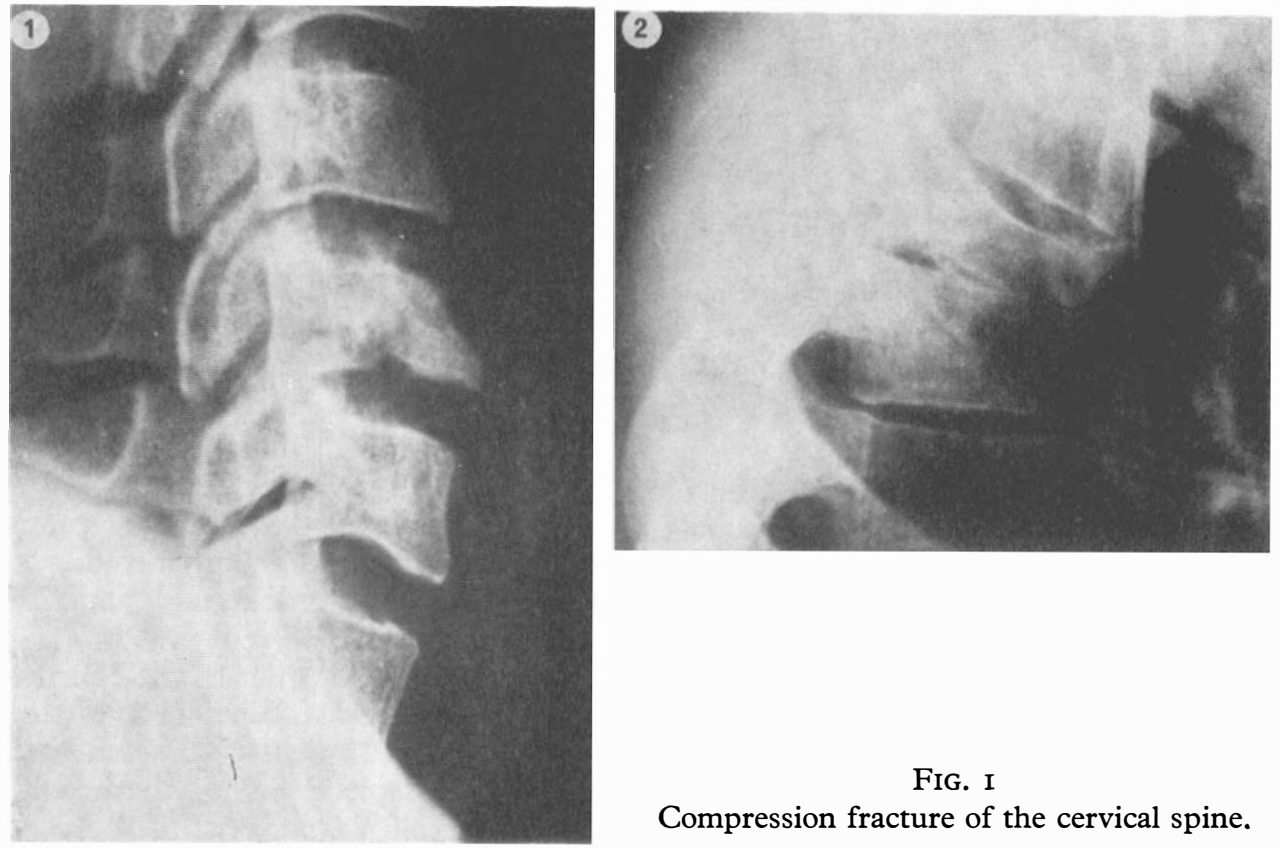

FIG. I

Compression fracture of the cervical spine.

FIG. 2

Compression fracture of the thoracic spine. 
TABLE VI

\begin{tabular}{lcc}
\hline Multiple thoracic fractures & I2 & $57 \%$ \\
Cervical t thoracic fractures & 2 & $9.5 \%$ \\
Dislocations and shearing type & II & $52 \%$ \\
\hline
\end{tabular}

* Three were cervical dislocations.
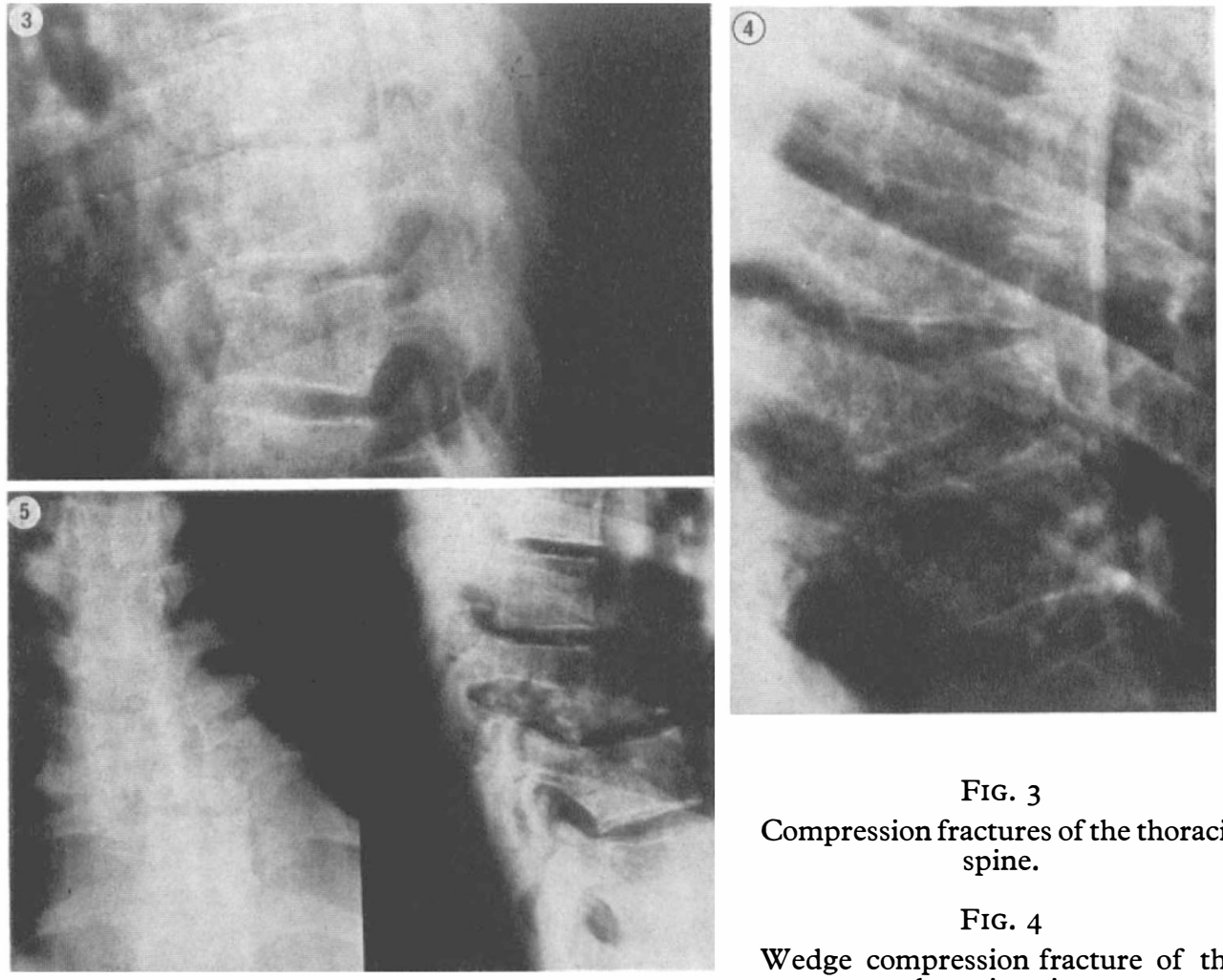

FIG. 3

Compression fractures of the thoracic spine.

FIG. 4

Wedge compression fracture of the thoracic spine.

FIG. 5

Antero posterior radiograph showing lateral dislocation (left) and lateral radiograph showing shearing type fracture of the thoracic spine.

orthopaedic and neurological incidences are due to the fact that 12 ( 75 per cent) of the thoracic vertebral injuries had multiple consecutive vertebrae involved.

Of the cervical injuries, two cases (40 per cent) were incomplete, both patients sustaining injuries at the fifth cervical level and both having full recovery.

Peak incidences of the thoracic spinal cord involvement were at the fourth, fifth, seventh and eighth spinal cord segments. Eight cases ( 50 per cent of the thoracic spinal injuries) occurred at the fourth or seventh spinal cord segments. Three (I9 per cent) of the thoracic lesions were incomplete, but of these only one managed without a wheelchair (Table VIII). In all, 8I per cent of thoracic 


\section{TABLE VII}

Neurological levels

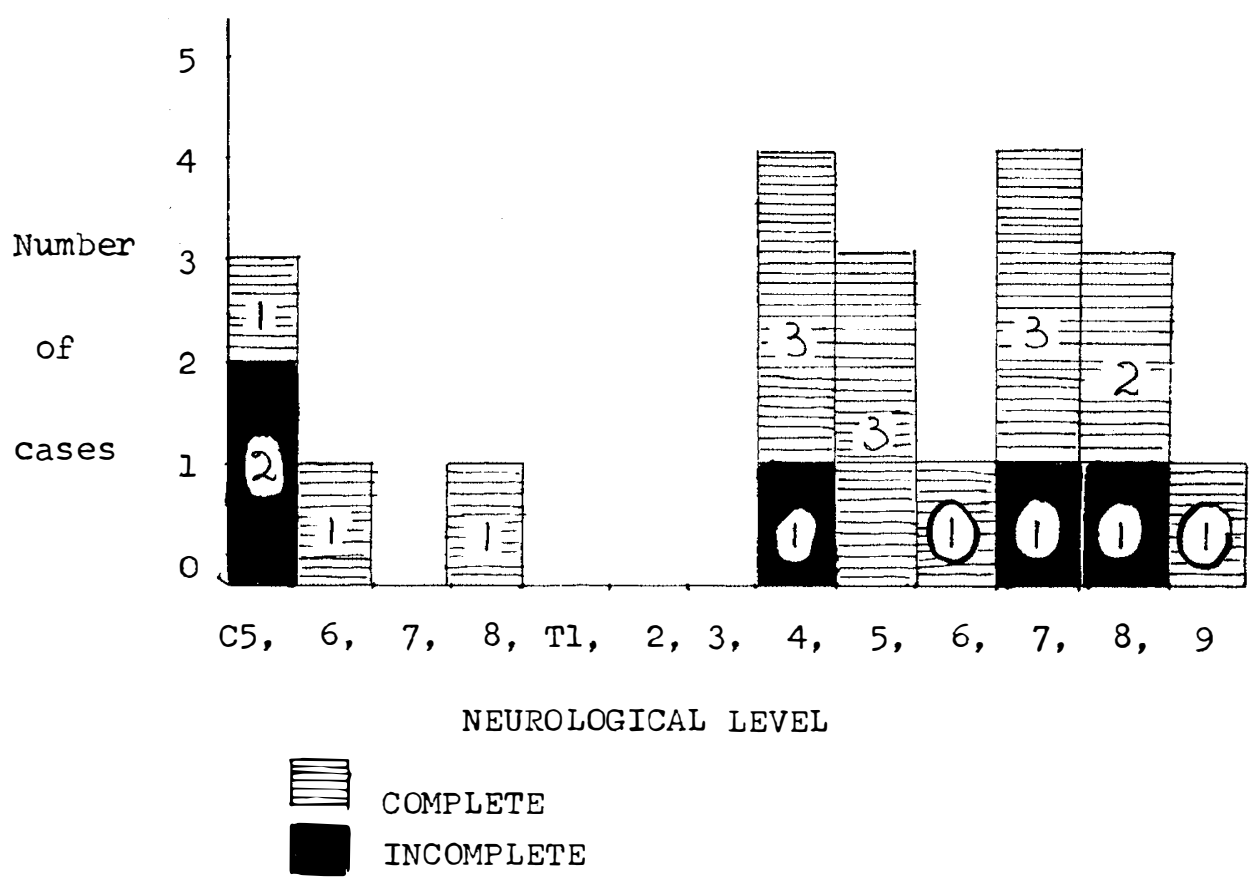

lesions were complete. Two complete thoracic lesions managed with above-knee calipers and elbow crutches. All other cases were wheelchair dependent.

\section{Associated Injuries}

Thoracic injuries are the result of extreme violence (Griffiths et al., I966; Hardy \& Rossier, I975) and multiple injuries are to be expected (Table IX). Three cases ( 14.2 per cent) had severe associated injuries necessitating long stays

TABLE VIII

Recovery

\begin{tabular}{lccc}
\hline & Cervical & Thoracic & Total \\
\hline Full recovery & 2 & - & 2 \\
Walking aids only & - & I & I \\
Walking aids + wheelchair & - & 2 & 2 \\
Wheelchair only & 3 & 12 & I5 \\
\hline
\end{tabular}

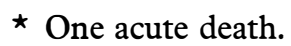


TABLE IX

Associated injuries

\begin{tabular}{llc}
\hline Abrasions and lacerations only & 9 & $43 \%$ \\
Lower limbs & 2 & $9 \cdot 5 \%$ \\
Upper limbs & 2 & $9 \cdot 5 \%$ \\
Fractured ribs & 9 & $43 \%$ \\
Head injuries & 4 & $19 \%$ \\
\hline
\end{tabular}

in the Intensive Care Unit. One of these developed fat embolus and another died of a pulmonary embolisation. Nine cases ( 43 per cent) had only minimal associated injuries-abrasions and lacerations. Two cases had lower limb fractures, one of whom had the tibia, fibula and femur involved on the same side (Figs. 6 and 7). Two cases had minor upper limb fractures.

Radiologically demonstrable fractured ribs were shown in nine cases (43 per cent) (Fig. 8), five having associated lung pathology (pneumo- or haemothorax, etc.). One case had a haemothorax with no radiological evidence of a rib fracture.

A common finding on radiographic examination of the patients with thoracic vertebral fractures was a paravertebral haematoma (Fig. 9) (Hardy \& Rossier,

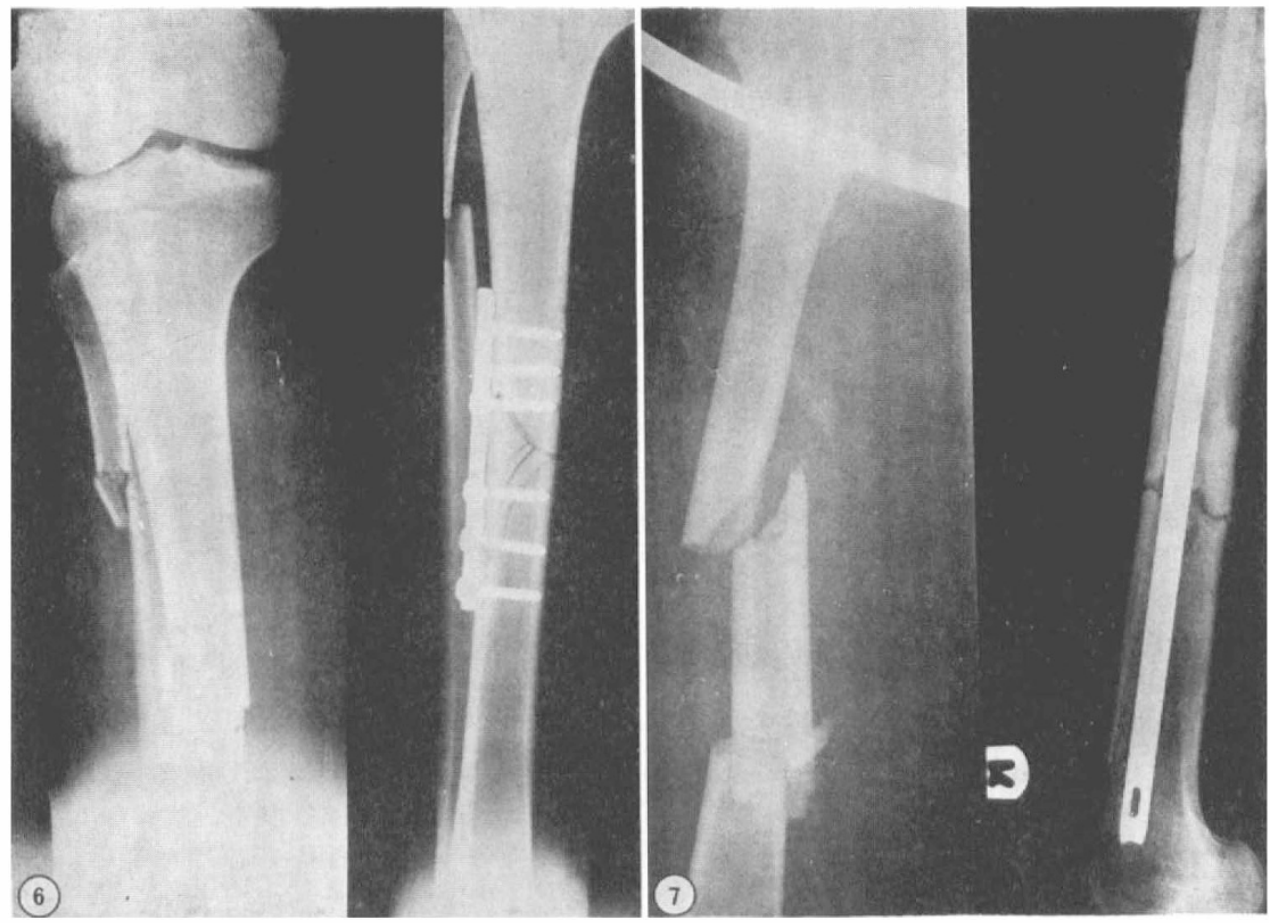

FIG. 6

Fractured tibia and fibula before and after internal fixation.

FIG. 7

Fractured femur before and after internal fixation. 


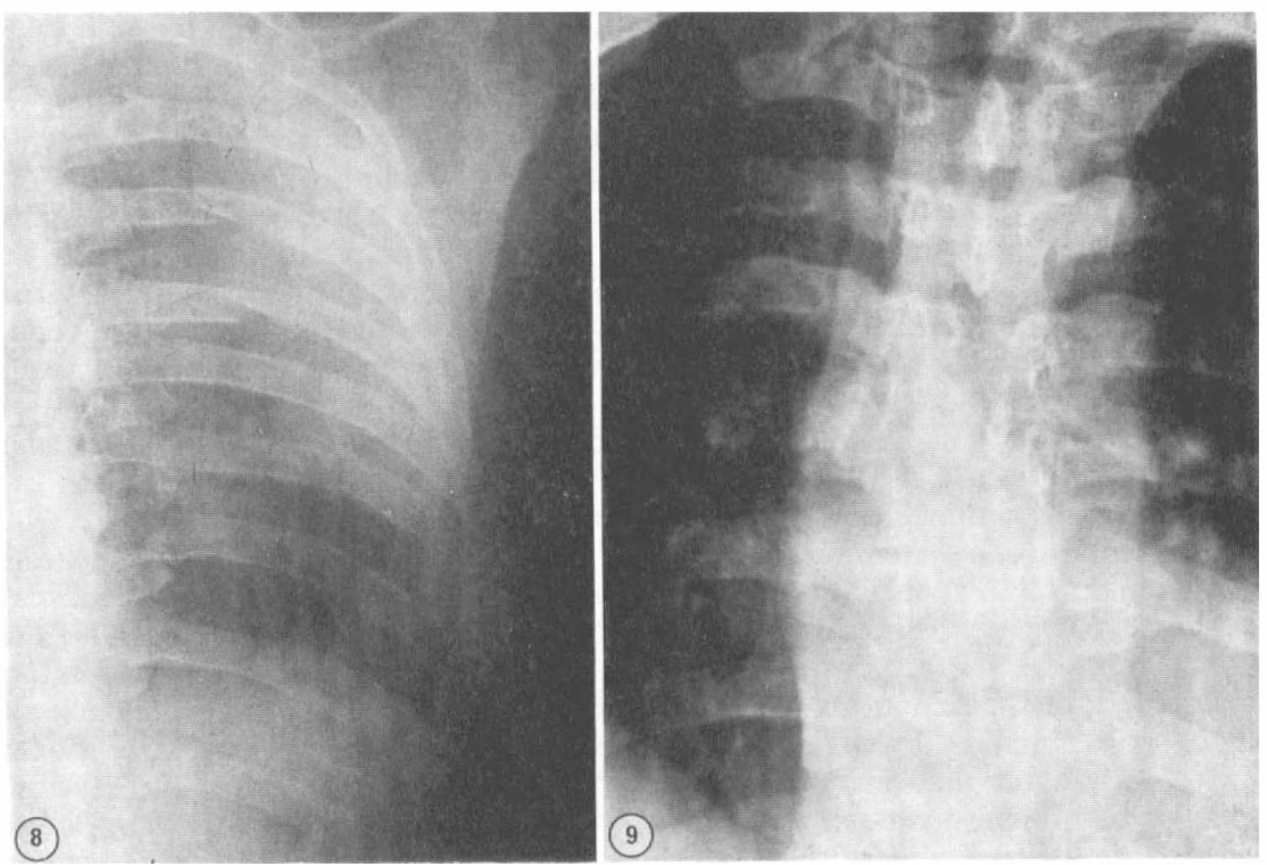

FIG. 8

Multiple fractured ribs associated with a fractured thoracic spine.

FIG. 9

Paravertebral haematoma associated with thoracic vertebral fractures.

1975). Of four cases presenting with minor head injuries, one had a fractured skull.

\section{Treatment}

The thoracic injuries, with one exception, were all treated conservatively by means of immobilisation on a pack bed for 12 weeks. The exception was a case transferred to the unit after an open reduction, plating and bone graft for a gross fracture-dislocation involving the T8/9 level.

Cervical lesions had skeletal or halter traction applied.

Fractures of long bones were treated by internal fixation in order to facilitate the nursing.

\section{Discussion}

With the rapid escalation in fuel costs since 1973, the motorcycle has become a popular means of economical transport. Forty-two per cent of the spinal cord injuries in this series occurred in the last 3 years and 6 months of this $13 \frac{1}{2}$-year period. A further possible reason for the high incidence after 1973 may be the compulsory wearing of standardised crash helmets from that date, with a resultant decrease in mortality due to associated head injuries.

The age incidence (66 per cent under the age of 25 years) is similar to that reported by other authors describing motorcycle accidents in general (Clark \& 
Morton, I97I; Deaner \& Fitchett, 1975; Drysdale et al., 1975). The high percentage of cases in the younger age group is possibly due both to lack of experience and the greater number of active motorcyclists below the age of 25 years.

The seasonal incidence also correlates with motorcycle accidents in general (Clark \& Morton, I97I; Deaner \& Fitchett, 1975).

Sixteen cases had fractures of the upper thoracic vertebrae (eight compression fractures and eight fracture-dislocations). In the Spinal Cord Injury Centre at Conradie Hospital these formed ro per cent of all upper thoracic vertebral fractures (TI-TIO), associated with spinal cord injury from any cause. Motorcycle accidents are therefore an important cause of fractures of the upper dorsal spine associated with paraplegia.

As stated by Griffiths et al. (1966), and Hardy and Rossier (1975), thoracic vertebral injuries are the result of extreme violence. In addition, Griffiths et al. showed that the upper dorsal spine is a stress area. Compression fractures of the vertebral bodies are caused by forces of violence applied through the head and shoulders. A motorcyclist in the normal sitting position on the motorcycle has a flexed spine. Should the motorcycle suddenly and unexpectedly hit an obstruction, the motorcyclist is projected off in the direction of motion of the motorcycle maintaining this flexed position to some extent. This position is probably exaggerated by flexing the head in an attempt to protect the face. Weir (1975) has shown that flexion of the head results in straightening of the cervical spine. The forward motion is stopped by striking a fixed object or the ground with the head or shoulders. Due to the speed of the motorcycle and the weight of the motorcyclist the force of impact is extreme. The initial force of impact is absorbed by the crash helmet and the straightened cervical spine (resulting in a possible cervical compression fracture) while the remainder of the body mass is still moving forwards. Since the relatively fixed dorsal kyphosis is the area of maximal curvature of the spine nearest the fixed point of impact, it is the site of maximal stress, which may therefore fracture as a result of further forced flexion, especially at its apex (T6 or T5), when the momentum of the rest of the body mass is dissipated along the long axis of the spine. This results in wedge compression fractures often at multiple levels. Burst fractures are rare in the thoracic spine due to the fixed dorsal kyphosis (Norrell, 1975). Four cases with wedge compression fractures remember hitting the road surface or fixed object head first and that their crash helmets were damaged.

Complete forward dislocation is described by Roaf as due to a blow on the back. This may occur if the rider should fall on his back on any projection, e.g. kerb of the road. It may also occur in a fall from a height with the upper part of the back hitting the ground first (Roaf, 1976). This is analogous with a motorcyclist being projected forward at speed, somersaulting and landing on his shoulders. The associated fractures of the ribs indicate a powerful force (Roaf, I976).

Lateral dislocation is probably similarly caused, except that there is an added element of rotation. Two patients could accurately remember what happened at the time of accident. The first patient skidded and came off the side of his motorcycle, while the second was actually looking behind him (i.e., rotated) when he rode into the rear of a truck.

Of the cervical vertebral injuries two had fractures of the vertical compression type and the other three had flexion-rotation type of injuries. The two double lesions both had compression fractures in the cervical and dorsal spine.

The increasing percentage of spinal injuries due to motorcycle accidents is probably due, both to the increased number of motorcyclists, and to the decreased 
mortality in motorcycle accidents as a result of the compulsory wearing of standardised crash helmets.

Eighty-one per cent of cases with thoracic lesions were neurologically complete. This is probably due to the smallness of the thoracic vertebral canal in relation to the spinal cord diameter and also to the tenuous blood supply to the upper thoracic spinal cord.

\section{Conclusion}

There has been an increased incidence of spinal cord injury as a result of motorcycle accidents since 1973 .

It has been shown that this is an injury of the younger age group-I 5 to 20 years. There is also a definite seasonal incidence with the emphasis on the summer months.

The most common site of injury is the upper thoracic spine maximally involving the sixth thoracic vertebra. The injury was the result of the motorcyclist being projected off the motorcycle at speed and landing on the head or upper part of the back.

The thoracic vertebral injuries were equally distributed between compression fractures and fracture-dislocations. Seventy-five per cent had more than one thoracic vertebral level involved. Double lesions do occur and usually involve cervical and thoracic spine.

The majority (8I per cent) of the neurological lesions of the thoracic spinal cord were complete. Sixty per cent of the cervical spinal cord injuries were complete.

\section{RÉSUMÉ}

Les lesions orthopédiques et neurologiques concernaut vingt et un cas de dommages sunenus à la moelle épinière résultat d'accidents motocyclistes sont en cours de revision. La colorme vertebrale et la moelle épinière dans la région thoracique furent les points atteints dans soixantescize per cent de cas. Quatre-vingt-un per cent de blessures thoraciques montrent des lesions complètement neurologiques. Un mecanisme traumatique est postulé.

\section{ZUSAMMENFASSUNG}

Es werden orthopädische und neurologische Verletzungen von 2 I Querschnittgelähonten Patienten nach Motoradunfällen beschrieben. In $76 \%$ der Fälle lag die Verletzung im Bereich der thorakalen Wirbel und Nervenstränge. 81\% der Verletzungen im thorakelen Bereich zeigten komplette neurologische Ausfälle. Ein sich-wiederholender Verletzungsmechanismus wird beschrieben.

Acknowledgments. I wish to thank Dr D. F. Smith, Medical Superintendent, Conradie Hospital for permission to publish and Dr A. G. Key and Dr A. T. Scher for their encouragement and advice in the preparation of this paper.

\section{REFERENCES}

Bothwell, P. W. (1960). Motor-cycle accidents. Lancet, 2, 807-809.

Clark, D. W. \& Morton, J. H. (I97I). The cycle accident: a growing problem. $\mathcal{F}$. Trauma, II, 230-237.

DeANER, R. M. \& Fitchett, V. H. (I975). Motorcycle trauma. F. Trauma, 15, 678-68I.

Drysdale, W. F., Kraus, J. F., Franti, C. E. \& RigGins, R. S. (I975). Injury patterns in motorcycle collisions. F. Trauma, 15, 99-I I5.

I6/I-H 
Griffiths, H. B., Gleave, J. R. W. \& Taylor, R. G. (I966). Changing patterns of fracture in the dorsal and lumbar spine. Brit. Med. F. $891-894$.

HARDY, A. G. \& Rossier, A. B. (1975). Spinal Cord Injuries: Orthopedic and Neurological Aspects. Georg Thieme Publishers, Stuttgart.

LA CAVA, G. (I96I). A clinical and statistical investigation of traumatic lesions due to sport. F. Sports Med. and Phys. Fitness, I-2, 8-15.

LODGE, T. (1976). Radio-diagnosis in patients with spinal injuries. In Handbook of Clinical Neurology, Vol. 26. Injuries of the spine and spinal cord, Part II, ed. P. J. Vinken and G. H. Bruyn. North Holland Publishing Co., Amsterdam, p. 263-283.

NoRRELl, H. A. (I975). Fractures and dislocations of the spine. In The Spine. W. B. Saunders, Philadelphia, p. 557.

ROAF, R. (1976). Biomechanics of injuries to the spinal column. In Handbook of Clinical Neurology, Vol. 25. Injuries of the spine and spinal cord, Part I, ed. P. J. Vinken and G. M. Bruyn. North Holland Publishing Co., Amsterdam, pp. I23-I40.

WeIR, D. C. (I975). Roentgenographic signs of cervical injury. Clinical Orthopaedics and Related Research, 109, 9-I 7. 